\begin{tabular}{|c|c|c|}
\hline \multirow{3}{*}{$\begin{array}{r}\text { Case Reports in } \\
\text { Gastroenterology }\end{array}$} & \multirow{2}{*}{\multicolumn{2}{|c|}{ Case Rep Gastroenterol 2017;11:791-796 }} \\
\hline & & \\
\hline & $\begin{array}{l}\text { DOI: } 10.1159 / 000485558 \\
\text { Published online: March 1, } 2018\end{array}$ & $\begin{array}{l}\text { (c) } 2017 \text { The Author(s) } \\
\text { Published by S. Karger AG, Basel } \\
\text { www.karger.com/crg }\end{array}$ \\
\hline & \multicolumn{2}{|c|}{$\begin{array}{l}\text { This article is licensed under the Creative Commons Attribution-NonCommercial } 4.0 \\
\text { International License (CC BY-NC) (http://www.karger.com/Services/OpenAccessLicense). } \\
\text { Usage and distribution for commercial purposes requires written permission. }\end{array}$} \\
\hline
\end{tabular}

\title{
Adenosquamous Carcinoma of the Colon
}

\author{
Tagore Sunkara $^{\mathrm{a}} \quad$ Megan E Caughey $^{\mathrm{b}}$ Priyanka Makkar $^{\mathrm{b}}$ Febin John $^{\mathrm{a}}$ \\ Vinaya Gaduputi \\ ${ }^{a}$ Division of Gastroenterology and Hepatology, The Brooklyn Hospital Center, Clinical \\ Affiliate of The Mount Sinai Hospital, Brooklyn, NY, USA; ${ }^{b}$ Division of Gastroenterology \\ and Hepatology, SBH Health System, Bronx, NY, USA
}

\section{Keywords}

Adenosquamous carcinoma Adenocarcinoma Squamous cell carcinoma Colon cancer

\begin{abstract}
Overall, colorectal cancer is the third most commonly diagnosed cancer in both men and women, meaning that it is one of the more widely recognized preventable cancers. Instances of colorectal malignancies though are overwhelmingly attributable to adenocarcinoma. Colorectal cancers with components of squamous cell carcinoma represent a statistical anomaly. Here, we present the case of a 50-year-old male, who complained of abdominal pain and weight loss over a 3-month period of time. Biopsies from a colonoscopy ultimately revealed that this patient's colon cancer consisted of both adenocarcinoma and squamous cell carcinoma, representing a truly exceptional pathology finding in a patient diagnosed with a colorectal cancer.

2017 The Author(s) Published by S. Karger AG, Basel
\end{abstract}

\section{Introduction}

Only $0.05-0.20 \%$ of colorectal malignancies show evidence of adenosquamous carcinoma (ASC) features [1]. Histologically, it is an exceedingly rare colorectal neoplasm, characterized by both glandular and squamous features. The symptomatic manifestations of ASC are much like those of colon adenocarcinomas, some of which include: abdominal pain, weight 
loss, changes in bowel habits, and hematochezia. Perhaps the most clinically relevant and important characteristic separating ASC from adenocarcinomas of the colon pertains to longterm cancer prognosis. The presence of ASC in a malignancy has been associated with poorer outcomes than the presence of adenocarcinoma alone within that same type of malignancy [2].

\section{Case Report}

A 50-year-old Caucasian male with no known past medical history presented to the emergency room with nonspecific complaints of nausea, non-radiating right lower quadrant abdominal pain of 1 week duration which was intermittent, 7/10 in severity with no exacerbating or reliving factors associated with weight loss of about 12 pounds in a span of 4 months. (Initial weight recorded in a clinic visit 4 months prior to the emergency room visit was $154 \mathrm{lbs}$ and the weight at the time of presentation to the emergency room was $142 \mathrm{lbs}$.) This patient also reported mild intermittent hematochezia (about 10-12 episodes) for a month and gave a pertinent history of colon cancer in his mother at the age of 50 . The patient's mother had undergone a left hemicolectomy with no recurrence on follow-up colonoscopies. Initial laboratory tests of the patient at the time of admission were significant for anemia with a hemoglobin of $9.9 \mathrm{~g} / \mathrm{dL}$, mean corpuscular volume of 79 , mild leukocytosis (leukocyte count of $15.8 \times 10^{3} / \mu \mathrm{L}$ ) and moderate transaminitis (aspartate aminotransferase of $72 \mathrm{U} / \mathrm{L}$ and alanine aminotransferase of $80 \mathrm{U} / \mathrm{L}$ ). A computerized tomography (CT) scan of abdomen and pelvis with contrast demonstrated multiple ring-enhancing lesions in both the right and left lobes of the liver (Fig. 1).

A diagnostic colonoscopy was subsequently performed and revealed the presence of a large, $5 \mathrm{~cm}$, non-circumferential and non-obstructive hepatic flexure mass (Fig. 2). Biopsies of the mass revealed solid nests of squamous carcinomatous components overlying adenocarcinomatous tissue, findings compatible with the diagnosis of adenosquamous cancer (Fig. 3). After a complete workup, the patient was diagnosed with stage IV poorly differentiated ASC of colon. He was started on palliative chemotherapy with fluorouracil and cisplatin. After 4 cycles, the patient elected to discontinue the chemotherapy because of gastrointestinal toxicities. Due to rarity of the condition, there were no standard treatment options to offer him, and most of the therapies were extrapolated from other squamous pathologies. Unfortunately, as a consequence of the advanced staging of his disease, the patient succumbed to the carcinoma.

\section{Discussion}

ASC is an uncommon disease that has the potential to affect different types of organs. It is a cancer identified by key histological features, some of which include: intracellular bridges, keratin pearl formation, glandular differentiation, and individual cell keratinization. For a malignancy to be identified as ASC, it must contain both adenocarcinoma and squamous cell carcinoma specimens. This can happen in several organ systems, resulting in a prognosis that varies considerably depending on which organ system is implicated. Additionally, the precise underlying pathogenesis of ASC remains unclear.

A study examining 576 cases of ASC in Taiwan determined it is most likely to affect the respiratory system (73.8\%), followed by the alimentary canal $(16.2 \%)$, and lastly, the female 
Sunkara et al.: Adenosquamous Carcinoma of the Colon

reproductive tract (10\%). As echoed by other studies, ASC within the gastrointestinal organs is considered an independent unfavorable prognostic factor when compared to adenocarcinoma [3]. Luckily, despite this, the likelihood of a patient being diagnosed with ASC of the colon or rectum is appreciably low. A recent NIH retrospective population study examined 111,263 total cases of adenocarcinoma and ASC of the colon and rectum. This study determined that $99.91 \%$ of these cases were adenocarcinoma, compared to a mere $0.09 \%$ of cases, which were ASC.

This NIH study also ruled out any possible correlation between cancer type and demographic characteristics, like sex, age, race, or socioeconomic status [4]. The previous study that examined ASC outcomes by system concluded that 16.3\% (94/576 ASC cases) were located within the alimentary canal. The three gastrointestinal organs that ASC was most commonly found in were the esophagus ( 24 cases), the colon (21 cases), and the oropharynx (16 cases) [3]. Within the colon specifically, the right colon and the transverse colon have been identified as locations where the majority of the colorectal cancers emerged [4]. Based on a sample of 21 patients with ASC, the average age of diagnosis within the colon was 58.8 years [3].

The long-term prognosis of colorectal ASC is often not favorable. Compared to adenocarcinoma, ASC is more likely to manifest with advanced disease and poor cellular differentiation [4]. Thus, ASC has a greater tendency to form both regional and distant metastases. Regional metastases have been shown to occur at a rate of $46.0 \%$, with distant metastases occurring at a similar rate of $42.4 \%$. The overall 5 -year survival rate of adenocarcinoma within the colon is $66 \%$, whereas that of ASC is only $31 \%$. This statistic best illustrates how compared to adenocarcinoma, ASC represents a worse prognosis [5]. Furthermore, at presentation, nearly half of the patients diagnosed with ASC already show evidence of metastases.

This fact speaks to the aggressive nature of colorectal ASC and the inevitable treatment difficulties it poses. The liver is the most common site of metastases from ASC located within the colon, followed by the peritoneum and the lung. Five-year survival outcomes vary tremendously with disease stage. Approximately $65 \%$ of those with disease stages I-III survive 5 years, while those with stage IV disease survive an average of 8.5 months [6].

The definitive treatment option for ASC of the colon is surgical resection. This typically involves removing the entire tumor in addition to regional mesenteric lymph nodes and possibly more, depending on the exact location of the malignancy [7]. The most challenging aspect of ASC treatment though is that due to its rarity, the specific roles of adjuvant chemotherapy and postoperative radiation remain unknown. The chemotherapeutic agents most frequently used to treat ASC are semustine, 5-fluorouracil, carmustine, and methotrexate. However, additional clinical trials are needed to optimize chemotherapy treatment protocols for ASC and to determine the exact extent of their clinical benefit [2].

\section{Statement of Ethics}

This case report was exempt from our Institutional Review Board as per its policy. Informed consent for participation was obtained from this patient. 


\section{Disclosure Statement}

None of the authors have any financial conflicts of interest. All authors have confirmed that the article is not under consideration for review at any other journal.

\section{Author Contributions}

All authors have made contributions to the article and have reviewed it before submission. Data relating to this case report is available from the corresponding author upon request.

\section{References}

1 Petrelli NJ, Valle AA, Weber TK, Rodriguez-Bigas M: Adenosquamous carcinoma of the colon and rectum. Dis Colon Rectum 1996;39:1265-1268.

$\checkmark 2$ Kang DB, Oh JT, Jo HJ, Park WC: Primary adenosquamous carcinoma of the colon. J Korean Surg Soc 2011;80:531-535.

3 Lan Y, Huang K, Liu C, Tai L, Chen M, Chao Y, Li A, Chiou S, Shyr Y, Wu C, Fang W: A nation-wide cancer registry-based study of adenosquamous carcinoma in Taiwan. PLoS ONE 2015;10:1-13.

$\checkmark 4$ Masoomi H, Ziogas A, Lin B, Barleben A, Mills S, Stamos M, Zell J: Population-based evaluation of adenosquamous carcinoma of the colon and rectum. Dis Colon Rectum 2012;55:509-514.

$\checkmark 5$ Cagir B, Nagy MW, Topham A, Rakinic J, Fry RD: Adenosquamous carcinoma of the colon, rectum, and anus: epidemiology, distribution, and survival characteristics. Dis Colon Rectum 1999;42:258-263.

$\checkmark 6$ Frizelle FA, Hobday KS, Batts KP, Nelson H: Adenosquamous and squamous carcinoma of the colon and upper rectum: a clincila and histopathologic study. Dis Colon Rectum 2001;44:341-346.

$\checkmark 7$ Shafaghi A, Askari K, Ashoobi M, Mansour-Ghanaei F: Adenosquamous carcinoma of the sigmoid colon: a case report and review of literature. Int J Clin Exp 2013;6:390-392. 


\begin{tabular}{|c|c|c|}
\hline \multirow{2}{*}{$\begin{array}{r}\text { Case Reports in } \\
\text { Gastroenterology }\end{array}$} & \multicolumn{2}{|c|}{ Case Rep Gastroenterol 2017;11:791-796 } \\
\hline & DOI: $10.1159 / 000485558$ & $\begin{array}{l}\text { O } 2017 \text { The Author(s). Published by S. Karger AG, Basel } \\
\text { www.karger.com/crg }\end{array}$ \\
\hline
\end{tabular}

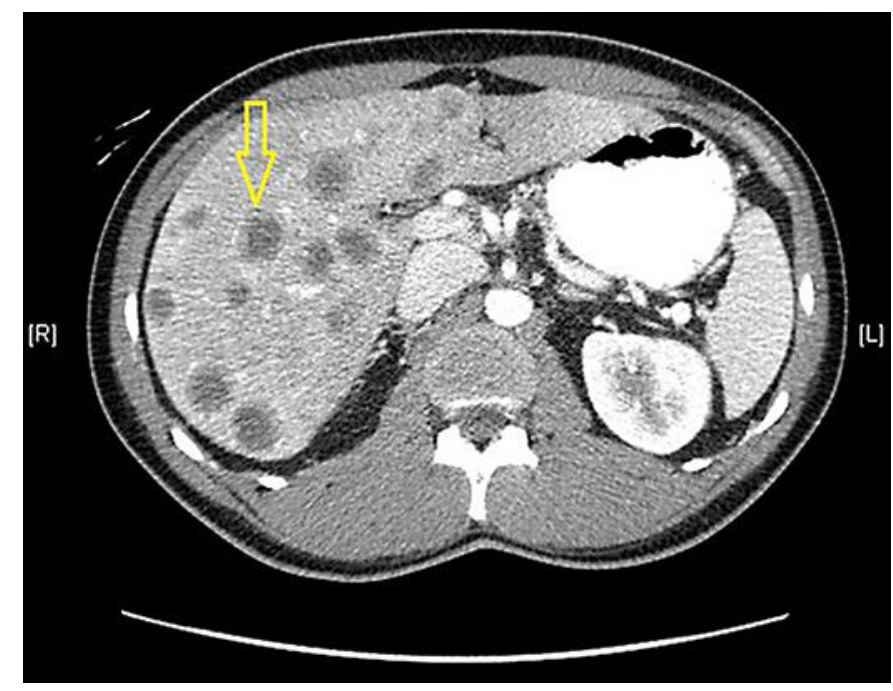

Fig. 1. CT scan of abdomen and pelvis with contrast showing multiple hepatic ring-enhancing lesions on the right and left liver lobe (yellow arrow).

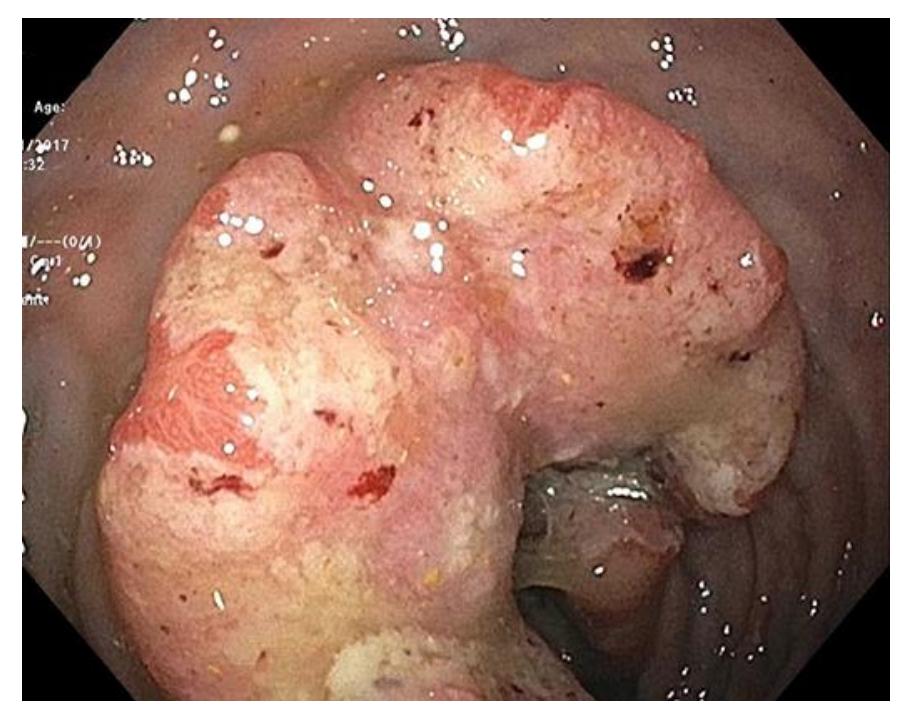

Fig. 2. Diagnostic colonoscopy revealing a 5-cm hepatic flexure mass. 


\section{Case Reports in Gastroenterology

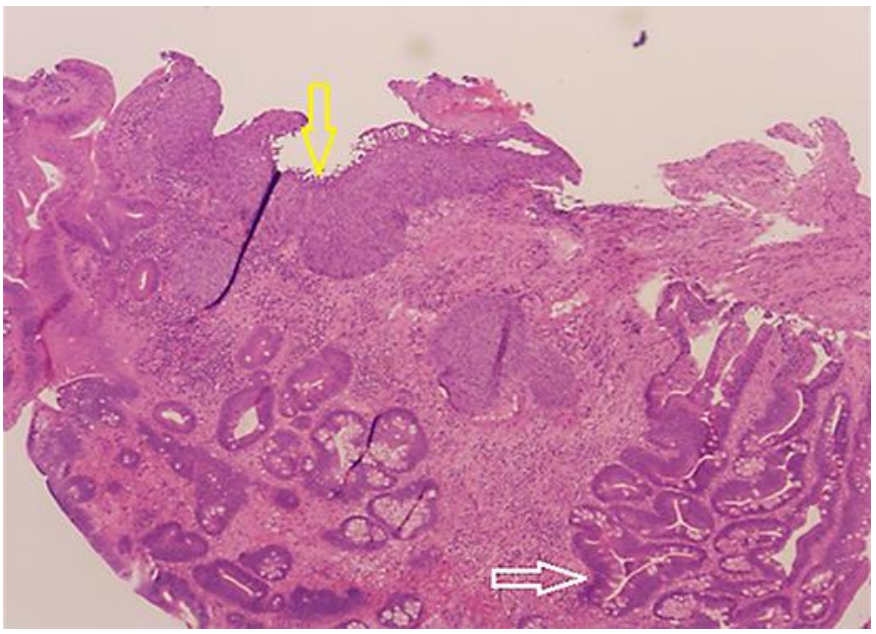

Fig. 3. Colon mass biopsies (hematoxylin and eosin stain, 40× magnification) showing solid nests of squamous components (yellow arrow) with underlying glandular and tubular structures (white arrow) signifying the adenomatous component. 